\title{
Environmental Impact of Fresh Vegetables Supply: A Case-Study in Teresina, Brazil
}

\author{
Manoel Eulálio Neto ${ }^{1,2}$, Irenilza de Alencar Nääs ${ }^{1^{*}}$, Nilsa Duarte da Silva Lima ${ }^{1}$
}

\author{
${ }^{1}$ Universidade Paulista, BRAZIL \\ ${ }^{2}$ Centro Universitário Santo Agostinho - FSA, BRAZIL \\ *Corresponding Author: irenilza.naas@docente.unip.br
}

Citation: Eulálio Neto, M., Nääs, I. d. A. and Lima, N. D. d. S. (2021). Environmental Impact of Fresh Vegetables Supply: A Case-Study in Teresina, Brazil. European Journal of Sustainable Development Research, 5(3), em0160. https://doi.org/10.21601/ejosdr/10951

ARTICLE INFO

Received: 28 Jan. 2021

Accepted: 27 Mar. 2021

\begin{abstract}
The current study presents an estimated environmental impact of $\mathrm{CO}_{2}$ emissions in the cargo transport process in the road modal, as part of the logistics chain for the distribution of horticultural items, highlighting the production of tomatoes (Solanum lycopersicum), lettuce (Lactuca sativa), peppers (Capsicum annuum) and cucumbers (Cucumis sativus), from production centers in several Brazilian states to a food distribution center in Teresina, Northeast Brazil. In the next step, we added fresh vegetables purchased by an urban hospital at the distribution center to analyze the city's food distribution system's environmental impact. The data used were obtained at the distribution center Nova Ceasa and at an urban hospital to complete the last stage of the food distribution, corresponding to 2019. The Global Warming Potential (GWP) impact values correlated with horticulture production were recovered from the literature related to open-field vegetable crops under similar agricultural conditions. We computed the quantity of vegetables produced on-field, the distances traveled, the on-road transportation fuel, and the environmental impact using the GWP calculator. The study found a wide range of GWP values. From the studies and analyzes, the results indicated that the impact of GWP is greater in the production phase in the field, followed by urban transport except for fresh tomatoes. The tomato results showed greater environmental impact in the transport of more distant products and smaller quantities. Results suggest that crop production and the long traveled distances are the main factors in the environmental impact. We also concluded that the greater the amount of product transported in a trip, the lower the environmental impact.
\end{abstract}

Keywords: CO2 emissions, GWP, logistic, agri-food supply chain

\section{INTRODUCTION}

In the last decade, consumers' demand for sustainable food has increased, and farmers and other actors of the agri-food supply chains need to understand where the environmental impacts come from and how to deal with them to improve production systems and distribution (Gunady et al., 2012). In recent years, several studies aimed to assess the environmental impact of agri-food production (Martin-Gorriz et al., 2020; Romero-Gámez et al., 2014; Venkat, 2012), mainly using life cycle assessment (LCA).

\section{Food Distribution and Logistics}

Both centralization and specialization in food production occur on a global scale, fueled by the economy of comparative advantage. Geographical distances between food producers and consumers are continually increasing. The agri-food system's globalization has established that food is transported long distances before reaching the consumer (Singh et al.,
2015). It is estimated that each food item distances itself from consumer products today by $50 \%$ more than in the $1980 \mathrm{~s}$ (Raven and Lang, 1995; Strome et al., 2016).

The transport and marketing of fresh horticulture products are complex and risky operations due to the products' perishable nature, seasonal production, and volume. The producer-to-consumer price spectrum, which results from the demand and supply of transactions between various intermediaries at different levels in the marketing system, is also unique to vegetables. Besides, marketing agreements at different stages also play an essential role in price levels at various stages, from the farm gate to the end-user. These resources make the fruit and vegetable marketing system different from other agricultural products, mainly in time, shape, and space utilities, in Brazil and other countries (Rais and Sheoran, 2015).

The globalization of the economy and the market's opening have caused changes and transformations in the world and Brazilian markets, making them more competitive 
and demanding. The advances and popularization of technology, the increase in competitiveness, and consumers' organized movement have marked the business management process's consequences. In response to this scenario, companies have been rethinking and modifying their management models to rationalize resources and maximize operational efficiency. For some branches of activity, logistics, quality management, and supply chain management present themselves as essential elements for the survival and improvement of companies' performance in a complex market. According to Wilmers (2011), global competition has been transforming the quality and supply chain management function from a support activity to an essential skill situation in which a company is viewed globally.

The management of the supply chain becomes imperative in searching for management efficiency and effectiveness, especially regarding perishable foods, given the scope and complexity of dealing with this product. There is a substantial increase in obstacles in the phase of distribution due to difficulties in ensuring product quality, in addition to this the need to maintain logistical costs and levels that enable greater quality control, especially in Northeast Brazil, with high temperatures throughout the year, which requires a mode of transport capable of preserving the quality of food and avoiding increased costs and waste. Kumar (2014) describes the risk in the supply chain, reporting how important it is to identify critical levels of risk to act and know how to manage it, considering the probability of interrupting the flow. Reis et al. (2016), referring to the commercialization of a particular product, highlights that farmers need to identify ways to commercialize their products at prices that bring profitability, even with logistical restrictions that may increase marketing costs. In this sense, the distribution channel's performance presents itself as a differential factor, enabling greater market competitiveness. Sehnem et al. (2015) point out that a traditional supply chain's effectiveness is measured based on its total cost and profitability, disregarding the impacts that the operations may cause to the environment. More emphasis should be on studies on the choice and strategies to reduce the on-road transport modal impact.

\section{Environmental Impact}

Transport is the logistical activity with an essential role within the supply chain as it enables sectors of the economy and the use of trucks to transport cargo can provide, in several situations, greater flexibility in the operations of distributing products and inputs in a more agile way, as it manages to cover almost all Brazilian regions. However, when it comes to the environmental issue, the transport operation deserves attention for its broad externalities, mainly as it is one of the most significant sources of polluting gases, especially $\mathrm{CO}_{2}$. Data from the Brazilian Ministry of Mines and Energy (Welle, 2018) indicate that in 2017 the total anthropogenic emissions associated with the Brazilian energy matrix reached a volume of 435.8 million tons of carbon dioxide equivalent $\left(\mathrm{Mt} \mathrm{CO}_{2}\right.$-eq),

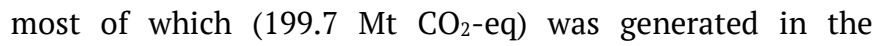
transport sector.

Global warming potential (GWP) is an index (GHG, 2011) that measures how much heat a greenhouse gas retains in the atmosphere up to a specific time horizon concerning carbon dioxide emissions, and which uses the $\mathrm{CO}_{2}$ value of 1 . The Intergovernmental Panel report on Climate Change (IPCC, 2014) considers that greenhouse gas (GHG) emissions should be reduced within the $40-70 \%$ range by 2050 from 2010 levels to avoid a temperature rise greater than $2{ }^{\circ} \mathrm{C}$ global average. Investigating the impact of GWP on food transport in Brazil, Duarte et al. (2019) indicate that the greater the amount of product transported by a trip, the lower the long-term environmental impact. As the production centers are very distant from the distribution center, in the case of the products studied in this research (tomatoes, lettuce, peppers, and cucumbers), the transport method used was the road, in many route options, which limits optimization strategies logistics for the transportation of these foods aiming at lower emission of polluting gases. The road transport sector handles about $60 \%$ of all freight in Brazil (Welle, 2018). Diesel road trucks travel huge distances from the farms to the food distribution centers in metropolitan areas, with the undeniable contribution of cargo transportation to Brazilian food distribution usually located in metropolitan areas.

However, to mitigate greenhouse gas emissions, companies must adopt strategies to use this transport modal better. Transport companies must seek improvement and optimization of their routes that include shorter distances between the origin and the destination point; make use of electric vehicles; opt for new energy sources to replace fossil fuels (diesel) in the energy use matrix, which will undoubtedly contribute to the reduction of $\mathrm{CO}_{2}$ emissions, and consequently, less aggression to the environment. Dias (2011) infers that environmental management improves a company's performance, allowing it to enter more demanding markets in ecological, environmental, and sustainability aspects and improve the public image.

In the quest to reduce the environmental impact, a 'local food' chain can be an alternative. Fornazier et al. (2015) indicate that the 'local food' system can be understood on the economic side as inducing cost reduction; on the sociologicalrural side, it strengthens social ties and greater proximity of information between producers and, on the environmental side, the consumption of less energy in transport and reduction of GHG emissions. However, it is still a challenge in continental countries such as Brazil (Duarte et al., 2019).

\section{Paper Outline}

The present study aimed to estimate the environmental impact on $\mathrm{CO}_{2}$ emissions in the freight transport process in the road modal, as part of the logistics chain for the distribution of some horticultural items, highlighting the production of tomatoes (Solanum lycopersicum), lettuce (Lactuca sativa), bell peppers (Capsicum annuum), and cucumbers (Cucumis sativus), production centers in several Brazilian states to a distribution center in Teresina, Piauí State, Northeast Brazil. In the next step, we added fresh vegetables bought from a hospital in the distribution center to analyze the city's food distribution system's environmental impact. We state the methods used in the research and the data recording and analysis. We show the environmental impact of fresh vegetables from the production farms to the distribution center in Teresina, Brazil, and further from the distribution center to a hospital in the urban area. 


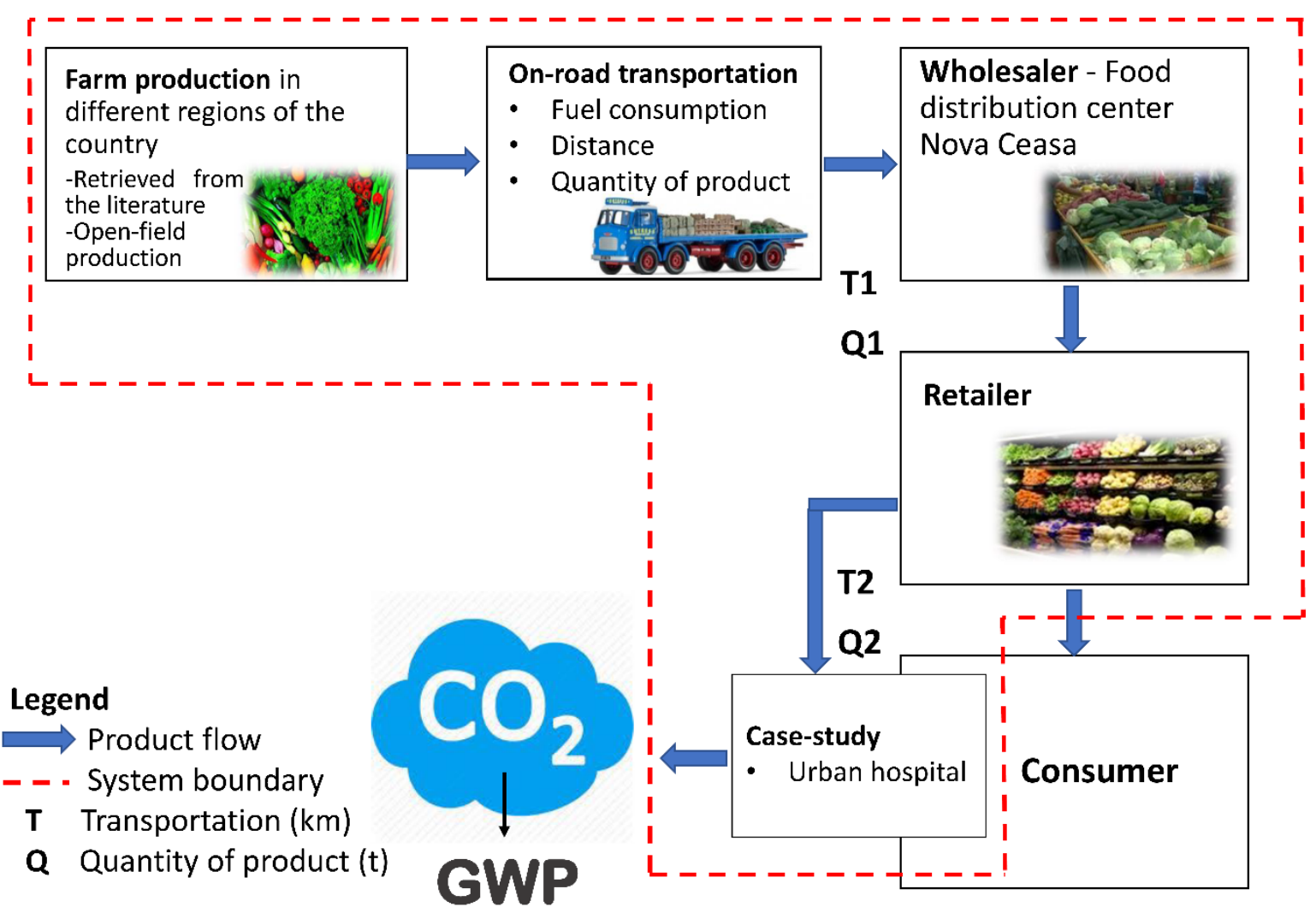

$\mathrm{T} 1=$ transport from farm to the distribution center; $\mathrm{Q} 1=$ quantity of products transported during $\mathrm{T} 1$ $\mathrm{T} 2=$ transport from the distribution center to the urban hospital; Q2=quantity of products transported during $\mathrm{T} 2$

Figure 1. Research model and system boundaries with the steps taken from data recording on farms to the food distribution center and the transport from the distribution center to an urban hospital

Table 1. Values of the GWP ( $\mathrm{kg} \mathrm{CO}_{2}$-eq/kg product) data from the studied vegetable production in open-field crops

\begin{tabular}{ccccc}
\hline Authors & Tomato & Lettuce & Bell pepper & Cucumber \\
\hline Nemecek et al. (2012) & - & - & 0.200 & - \\
\hline Venkat (2012) & - & 0.192 & - & - \\
\hline Romero-Gámezet al (2014) & - & 0.026 & - & - \\
\hline Theurl et al. (2014) & - & 0.025 & - & - \\
\hline Stajnko et al. (2016) & 0.162 & - & - & - \\
\hline Clune et al. (2017) & 0.460 & 0.380 & -520 & - \\
\hline Pishgar-Komleh et al. (2017) & 0.340 & - & - & - \\
\hline Ali et al. (2019) & - & - & - & - \\
\hline Pineda et al. (2020) & 0.542 & - & - & - \\
\hline Martin-Gorriz et al. (2020) & - & 0.095 & - & - \\
\hline Nicholson et al. (2020) & - & 0.023 & $\mathbf{0 . 3 6 0}$ & -1735 \\
\hline Average values & $\mathbf{0 . 3 7 6}$ & $\mathbf{0 . 1 2 3 5}$ & & $\mathbf{0 . 1 7 3 5}$ \\
\hline
\end{tabular}

\section{RESEARCH QUESTIONS, MODEL AND METHODS}

\section{Research Questions and Model}

The two research questions in the present study are:

- What is the GWP impact of vegetable products (tomato, bell pepper, and cucumber) from the farm to the distribution center in Teresina, Brazil?

- Does the food delivery from the distribution center to a local urban hospital substantially decrease the environmental impact?
Figure 1 shows the investigation model we use to respond to these questions.

\section{Methods}

GWP values correlated to the horticulture production were retrieved from the current literature related to open-field vegetable crops (Table 1). Fresh vegetable on-field production processes usually include the energy equivalent values from the farm inputs (chemicals, fertilizers, inputs from irrigation, and machinery for cultivation, harvesting, processing, and refrigeration). GWP assessment output, expressed in $\mathrm{CO}_{2}$ equivalent, contains nitrogen emitted from fertilized soils and other GHG emissions from crops (Clune et al., 2017). We searched for data on open-field conventional vegetable crops 


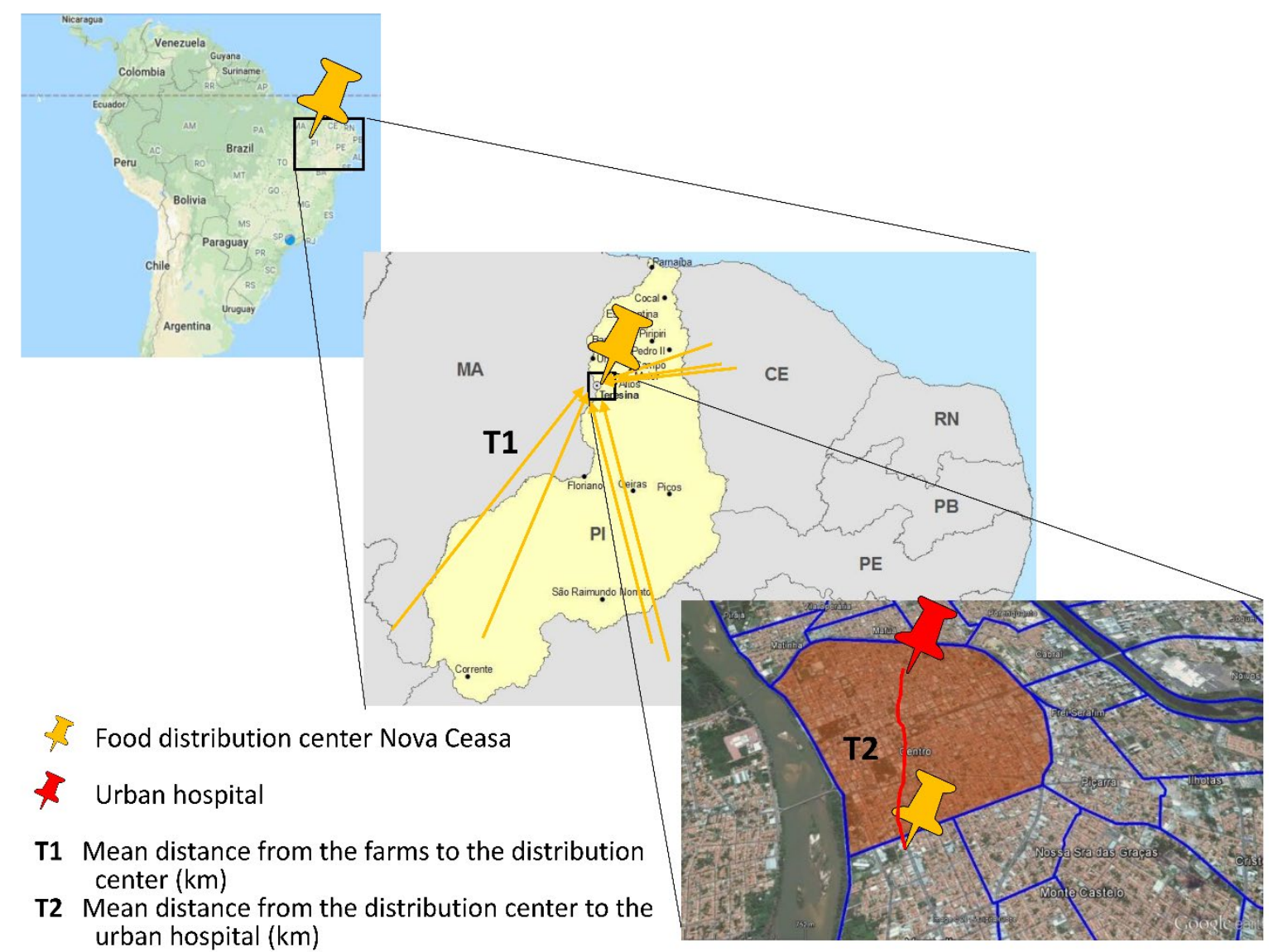

Figure 2. Schematic view of the two transportation routes, from farms to distribution center, and from the distribution center to the urban hospital

using the optimal recommended amount of $\mathrm{N}$ fertilizer applied and minimal pesticide use. We found a wide range of GWP values in the literature for vegetable crops under similar agricultural conditions. For instance, GWP for lettuce ranged from 0.095 (Martin-Gorriz et al., 2020) to $0.380 \mathrm{~kg} \mathrm{CO}_{2}$ eq (Clune et al., 2017). For estimating the GWP (kg CO $2-e q / k g$ product), we used the average values.

We acquired data from the distribution center (Nova Ceasa, Teresina, $5^{\circ} 5^{\prime} 20^{\prime}$ S, $42^{\circ} 48^{\prime}$ 7” $\mathrm{W}$, and $72 \mathrm{~m}$ altitude, Brazil) from January to December 2019 of four fresh vegetables, tomato, lettuce, bell pepper, and cucumber. Those vegetables were selected as there was a complete record of them transported from production areas without being mixed with other products. These products were brought from different regions of the country. We selected the data from open-field production of vegetables transported using on-road transport employing cargo trucks from the production centers to the distribution center (Nova Ceasa) in Teresina (Figure 2).

A diesel pickup was used to transport the distribution center to the urban hospital. It had an average fuel consumption in the urban area of $6.5 \mathrm{~km} / \mathrm{L}$ and covered a distance of $32.6 \mathrm{~km}$, on average, nine times/month, in a round trip. Table 2 shows the average quantities of products and distances traveled from the farms where the vegetables are produced to the distribution center and from the center to the urban hospital. The food was transported from the production regions in trucks with a capacity of $8 \mathrm{t}$, with an average consumption of $10 \mathrm{~L}$ of diesel oil, and the GWP was calculated
Table 2. Products, mean quantity of the products (Q1 and Q2, $\mathrm{t})$, mean distance traveled from the farms to the distribution center $(\mathrm{T} 1, \mathrm{~km})$, and mean distance from the distribution center to the urban hospital $(\mathrm{T} 2, \mathrm{~km})$

\begin{tabular}{|c|c|c|c|c|}
\hline Product & Q1 (t) & T1 (km) & Q2 (t) & T2 (km) \\
\hline Tomato & 647.8 & 41623.7 & 0.81 & \multirow{4}{*}{3520.0} \\
\hline Lettuce & 651.0 & 26259.1 & 0.45 & \\
\hline Bell pepper & 145.1 & 4629.0 & 0.27 & \\
\hline Cucumber & 115.2 & 3267.1 & 0.21 & \\
\hline
\end{tabular}

$\mathrm{Q} 1=$ mean quantity of product transported from the production area to the distribution center $(\mathrm{t})$; $\mathrm{T} 1=$ mean distance from the farms to the distribution center; $\mathrm{Q} 2=$ mean quantity of product transported from the distribution center to the urban hospital $(\mathrm{t})$; $\mathrm{T} 2=$ mean distance from the distribution center to the urban hospital $(\mathrm{km})$. All values refer to products transported during 2019.

using the online calculator (CFC, 2018). The online calculator allows the user to enter the distance traveled and the average fuel consumption, and the result is the amount of $\mathrm{t} \mathrm{CO}_{2}$ eq/year, which is the GWP in 100 years. Transport distances were estimated, and $\mathrm{CO}_{2}$ emissions were calculated using the online calculator (CFC, 2018).

\section{RESULTS AND DISCUSSION}

Table 3 shows the details of the products, the distances from which they see the products (region of production), the quantity of the product, and the calculated GWP. The 


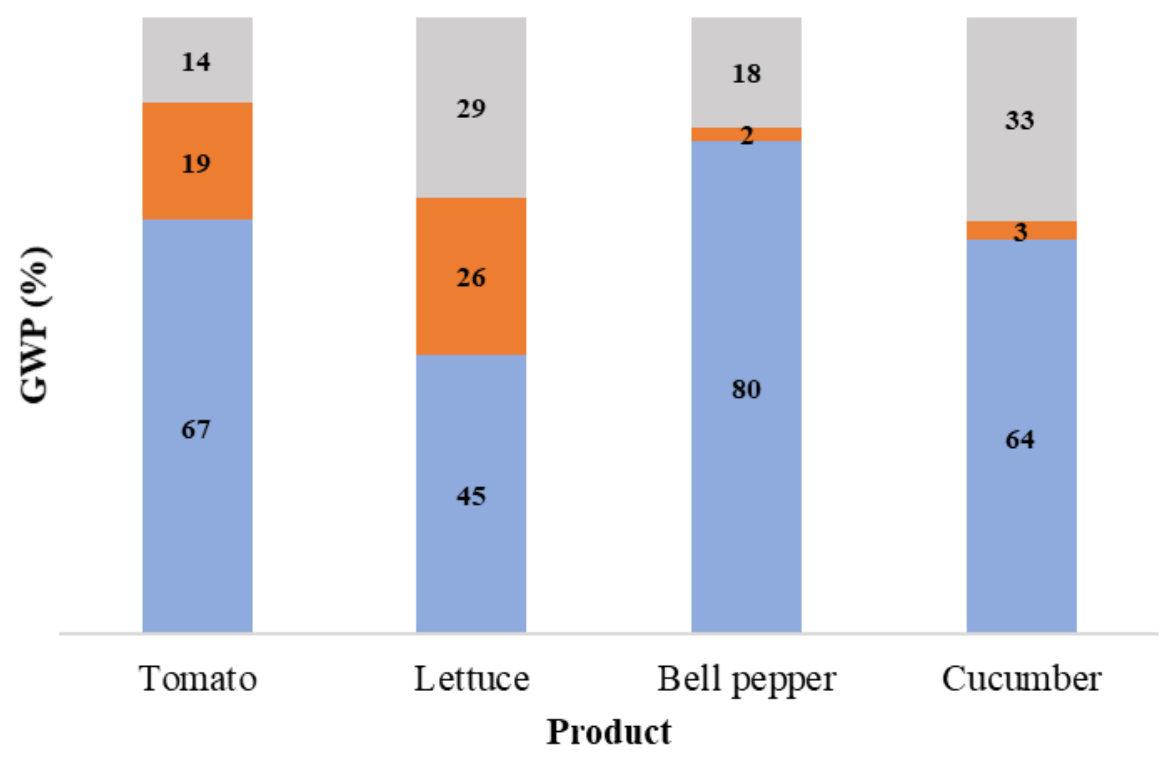

Open-field production $\quad \mathrm{T} 1 \quad \mathrm{~T} 2$

Figure 3. Global warming potential (GWP, \%) of the product's stages - from the production farms (cradle) to the urban hospital (fork) in Teresina, Brazil

calculated values are added to forecast the total GWP ( $\mathrm{t}$ in 100 years) for each studied vegetable. The total GWP represents the environmental impact of crop production and transportation, both interstate and urban shipments.

Using the calculated data, we developed a graph to show the GWP percentage in each chain segment (Figure 3). In all studied products, the environmental impact is higher during the production stage, followed by the transportation inside the metropolitan area. Since the volume of vegetables transported was quite large in tomatoes and lettuce, there was a GWP dilution by the product amount. However, in the metropolitan area, the scope changed, and the small amount transported presented a more considerable impact. The volume and distance of distribution of vegetables transported from the farm and from the distribution center to the consumer are directly related to the GWP increase. The smaller the volume of vegetables and the greater the distance, the higher is GWP in distribution. However, the total GWP depends on the characteristics of the production phase of each crop. Usually, the amount of energy equivalent input in the open-field soilpreparation, irrigation and fertilization, and harvesting management is related to fuel in equipment operations. In these stages, the fuel used in agricultural vehicles and tools for cultivation (sprayer, rotary cultivator, and plow) and crop management differ depending on the soil and region weather.

Looking at GWP values of the vegetable production phase, we can observe an increase in the total GWT, mainly for bell pepper and tomato (Table 3), as these crops required more intensive energy input.

The result found in the present study indicates that GWP impact is higher in the on-field production stage (Maraseni et al., 2010), as it involves all phases of crop production, followed by the values of urban transportation. The bell pepper was the vegetable whose GWP value in crop production is much higher
Table 3. Details of open-field crops products (tomatoes, lettuce, bell peppers, and cucumbers), mean quantity, mean distance transported, from the distribution center to urban hospital, and total GWP ( $\mathrm{t}$ in 100 years)

\begin{tabular}{ccccc}
\hline Product & $\begin{array}{c}\text { Open-field } \\
\text { production (kg CO }{ }^{-} \\
\text {eq/kg product }\end{array}$ & $\begin{array}{c}\text { GWP } \\
\text { from T1 }\end{array}$ & $\begin{array}{c}\text { GWP } \\
\text { from T2 }\end{array}$ & $\begin{array}{c}\text { Total } \\
\text { GWP (t in } \\
\text { 100 years) }\end{array}$ \\
\hline Tomato & 0.376 & 0.110 & 0.08 & 0.578 \\
\hline Lettuce & 0.124 & 0.070 & 0.08 & 0.274 \\
\hline Bell pepper & 0.360 & 0.010 & 0.08 & 0.450 \\
\hline Cucumber & 0.174 & 0.008 & 0.09 & 0.272 \\
\hline
\end{tabular}

Obs. The values refer to the total product transportation during the year of the study (2019); " Mean value from references in Table 1; Total GWP represents the GWP from production and transportation (T1 and $\mathrm{T} 2)$

than the transport environmental impact, followed by the tomato, cucumber, and lettuce. Lettuce was the vegetable with the highest GWP during the interstate on-road transportation than the other studied vegetables (tomato, bell pepper, and cucumber). The tomatoes' results agree with Duarte et al. (2019), who noticed values of greater environmental impact in transporting more distant products in smaller quantities. Different production scales can influence the environmental impact at the local, regional or global level (Morrow et al., 2010). Gunady et al. (2012) observed that the on-farm stage of lettuces production emitted approximately $13 \%$ of the total GHG emissions. In the present study, we estimate the value in $45 \%$, representing a variation of $32 \%$ in total, and the potential difference is due to the crop production scale and the wide variety of agricultural practices.

On the other hand, Foteinis and Chatzisymeon (2016) found a total contribution to environmental impacts of $42.7 \%$ in conventional lettuce cultivation systems, agreeing with the present research's value. In a systematic review, Clune et al. (2017) stated average and standard deviation values of the 
same scale for field-grown fresh vegetables $\left(0.37 \pm 0.39 \mathrm{CO}_{2}\right.$ $\mathrm{eq} / \mathrm{kg}$ ). Such a variation is expected, considering the broad flexibility in farming techniques, implicating differences in GWP values.

In our results for the fresh tomato, the GWP percentage on the farm was $67 \%$, while Pineda et al. (2020) suggest $62 \%$. Stajnko et al. (2016) found the GWP in tomato production varying from 16 to $47 \%$ depending on the production system. However, the authors imply that the overall environmental impact is mostly related to transportation rather than on-farm production. In the current study, we might infer that this assumption does not apply to our results since we found the highest value of GWP directly related to fresh tomatoes' onfield production.

The bell pepper and cucumber results indicate that the onfarm conventional production retains the most considerable impact (80 and 64\%, respectively). Since, in our case, the production is situated near the metropolitan area, a large amount of the product transported does not represent a large environmental impact. However, it appears a significant impact when small amounts are transported within the urban area. Nemecek et al. (2012) found substantial variability in GWP of worldwide crop production using a modular extrapolation approach, including bell pepper, and the variation is attributed to the most different agricultural systems adopted by various countries. Our results in the environmental impact on-field production of cucumber (64\%) differ from those of Ali et al. (2019), who found GWP values ranging from 17 to $20 \%$ depending on the farm size and agriculture crop system. Again, we understand the discrepancies' origin due to the differences in the farming processes and management (Clune et al., 2017).

It is worth mentioning that to improve the use of trucks to transport cargo, logistical activity with an essential role within the supply chain, it is essential to move forward in implementing strategies and tools that preserve the continuity of wealth generation for the country, but that hurt nature less.

\section{CONCLUSIONS}

We calculated the GWP impact of vegetable products (tomato, bell pepper, and cucumber) from the farm to the distribution center in Teresina, Brazil. The results indicated that the transport distance implies a greater environmental impact, being proportional to the transported load.

The food delivery from the distribution center to the urban hospital did not impact as much when compared to the GWP values recorded from the production farms to the distribution center. We recommend studies, tests, and practices that can also contribute to this process, such as drawing strategic routes, which include shorter distances between the origin and the destination point; use of electric vehicles; option for new sources of renewable energy for on-road cargo transportation in substitution for diesel oil, a fossil fuel generally used in Brazilian road transportation. Besides, seek to prioritize local production strategies, except for those situations in which there is no positive impact on the emission of gases that harm the environment.
Author contributions: All co-authors have involved in all stages of this study while preparing the final version. They all agree with the results and conclusions.

Funding: No external funding is received for this article.

Declaration of interest: The authors declare no conflict of interest.

Acknowledgements: The authors wish to thank Mr. Antônio de Lisboa Lopes de Araújo for his contribution by providing data and information related to the Santa Fé Clinic and Maternity urban hospital. In the same way, thank Ms. Juliana Querino Diniz, who kindly authorized the availability of Nova Ceasa distribution center data, which enabled the analyses extracted and present in this research.

Ethics approval and consent to participate: Not applicable. Availability of data and materials: All data generated or analyzed during this study are available for sharing when appropriate request is directed to corresponding author.

\section{REFERENCES}

Ali, Q., Yaseen, M. R. and Tariq Iqbal Khan, M. (2019). Energy budgeting and greenhouse gas emission in cucumber under tunnel farming in Punjab, Pakistan. Sci Hortic, 250, 168173. https://doi.org/10.1016/j.scienta.2019.02.045

CFC. Carbon Footprint Calculator. (2018). Vehicle $\mathrm{CO}_{2}$ emissions footprint calculator. Available at: https://www. commercialfleet.org/tools/van/carbon-footprintcalculator (Accessed: 20 January 2021).

Clune, S., Crossin, E. and Verghese, K. (2017). Systematic review of greenhouse gas emissions for different fresh food categories. J Clean Prod, 140, $766 \mathrm{e} 783$. https://doi.org/10.1016/j.jclepro.2016.04.082.

Dias, R. (2011). Environmental management: social responsibility and sustainability (2. Ed.). São Paulo: Atlas.

Duarte, G. T., de Alencar Nääs, I., Innocencio, C. M. et al. (2019). Environmental impact of the on-road transportation distance and product volume from farm to a fresh food distribution center: a case study in Brazil. Environ Sci Pollut Res, 26, 33694-33701. https://doi.org/10.1007/s11356-019-06461-8

Fornazier, A. and Belik, W. (2013). Local food production and consumption: new approaches and perspectives for public policies. Food Security and Nutrition. Segurança Alimentar e Nutricional, 20(2), 204-218. https://doi.org/10.20396/ san.v20i2.8634598

Foteinis, S. and Chatzisymeon, E. (2016). Life cycle assessment of organic versus conventional agriculture. A case study of lettuce cultivation in Greece. J Clean Prod, 112, $2462 \mathrm{e} 2471$. https://doi.org/10.1016/j.jclepro.2015.09.075

GHG - Protocol Standard (2011). The greenhouse gas protocol. Available at: http://www.ghgprotocol.org/standards (Accessed: 10 September 2020).

Gunady, M. G. A. Biswas, W., Solah, V. A. and James, A. P. (2012). Evaluating the global warming potential of the fresh produce supply chain for strawberries, romaine/cos lettuces (Lactuca sativa), and button mushrooms (Agaricus bisporus) in Western Australia using life cycle assessment (LCA). J Clean Prod, 28, 81-87. https://doi.org/10.1016/j.jclepro.2011.12.031 
IPCC- Intergovernmental Panel on Climate Change. (2014). Fifth Assessment Report (AR5). https://archive.ipcc.ch/ report/ar5/syr/

Kumar, S., Himes, K. J. and Kritzer, C. P. (2014). Risk assessment and operational approaches to managing risk in global supply chains. J Manuf Technol Manag, 25, 873890. https://doi.org/10.1108/JMTM-04-2012-0044

Maraseni, T. N., Cockfield, G., Maroulis, J. and Chen, G. (2010). An assessment of greenhouse gas emissions from the Australian vegetables industry. J Environ Sci Health, Part B 45, 578e588. https://doi.org/10.1080/03601234.2010. 493497

Martin-Gorriz, B., Gallego-Elvira, B., Martínez-Alvarez, V. and Maestre-Valero, J. F. (2020). Life cycle assessment of fruit and vegetable production in the Region of Murcia (southeast Spain) and evaluation of impact mitigation practices. J Clean Prod, 265, e121656. https://doi.org/10.1016/ j.jclepro.2020.121656

Morrow, W. R., Gallagher, K. S., Collantes, G. and Lee, H. (2010). Analysis of policies to reduce oil consumption and greenhouse-gas emissions from the US transportation sector. Energy Policy, 38, 1305-1320. https://doi.org/ 10.1016/j.enpol.2009.11.006

Nemecek, T., Weiler, K., Plassmann, K., Schnetzer, J., Gaillard, G., Jefferies, D., García-Suárez, T., et al. (2012). Estimation of the variability in global warming potential of worldwide crop production using a modular extrapolation approach. $J$ Clean Prod, 31, 106-117. https://doi.org/10.1016/ j.jclepro.2012.03.005

Nicholson, C. F., Harbick, K., Gómez, M. I. and Mattson, N. S. (2020). An economic and environmental comparison of conventional and controlled environment agriculture (CEA) supply chains for leaf lettuce to US cities. In: Aktas E., Bourlakis M. (eds) Food Supply Chains in Cities. Palgrave: Macmillan Cham. https://doi.org/10.1007/978-3-03034065-0_2

Pineda I. T., Cho J. H., Lee D., Lee S. M., Sangseok Yu S., Lee Y. D. (2020). Environmental Impact of Fresh Tomato Production in an Urban Rooftop Greenhouse in a Humid Continental Climate in South Korea. Sustainability 12, e9029. https://doi.org/10.3390/su12219029

Pishgar-Komleh, S.H., Akram, A., Keyhani, A., Raei, M., Elshout, P.M.F., Huijbregts, et al. (2017). Variability in the carbon footprint of open-field tomato production in Iran A case study of Alborz and East-Azerbaijan provinces. $J$ Clean Prod, 142, 1510-1517. https://doi.org/10.1016/ j.jclepro.2016.11.154
Rais, M. and Sheoran, A. (2015). Scope of supply chain management in fruits and vegetables in India. I Food Process Technol, 6(3), e1000427. http://omicsonline.org/ open-access/scope-of-supply-chain-management-infruits-and-vegetables-in-india-2157-7110-1000427.php? aid $=41037$

Raven, H. and Lang, T. (1995). Cheap food at a huge price. Resurgence, 171, 16-17. https://doi.org/10.1023/A:102560 7929777

Reis, J. G. M., Vendrametto, O., Nääss, I. A., et al. (2016). Evaluation of corn marketing strategies in ms using the Analytic Hierarchy Process (AHP). Revista de Economia e Sociologia Rural, 54, 131-146. https://doi.org/10.1590/ 1234-56781806-9479005401007

Romero-Gámez, M., Audsley, E., Elisa, M. And Suárez-Rey, E. M. (2014). Life cycle assessment of cultivating lettuce and escarole in Spain. J Clean Prod, 73, 193-203, https://doi.org/10.1016/j.jclepro.2013.10.053

Sehnem, S. and Oliveira, G. P. (2016). Green supply chain management: an analysis of the supplier-agro industry relationship of a Southern Brazilian Company. BBR. Brazilian Business Review, 13, 158-190. https://doi.org/10.15728/bbr.2016.13.6.1

Singh, S., Singh, D. R., Chand, S., Ajanta Birah, A. and Roy, D. (2015). Analysis of perspectives of self-sufficiency in vegetable production under tropical conditions. Int J Veg Sci, 21(1), 53-68. https://doi.org/10.1080/19315260.2013. 823585

Stajnko, D., Narodoslawsky, M. and Lakota, M. (2016). Ecological footprints and $\mathrm{CO}_{2}$ emissions of tomato production in Slovenia. Pol J Environ Stud, 25, 1-11. https://doi.org/10.15244/pjoes/61757

Strome, S., Johns, T., Scicchitano, M. J. and Shelnutt, K. (2016). Elements of access: The effects of food outlet proximity, transportation, and realized access on fresh fruit and vegetable consumption in food deserts. Int $Q$ Community Health Educ, 37(1), 61-70. https://doi.org/10.1177/ $0272684 X 16685252$

Venkat, K. (2012). Comparison of twelve organic and conventional farming systems: a life cycle greenhouse gas emissions perspective. J Sustain Agric, 36(6), $620 \mathrm{e} 649$. https://doi.org/10.1080/10440046.2012.672378

Welle, D. (2018). What represents the transport by trucks for Brazilian supply chains? Available at: https://www.carta capital.com.br/economia/o-que-o-transporte-por-caminh oes-representa-para-o-brasil (Accessed: 15 October 2020). 